\title{
Infrared and Raman spectroscopic characterization of the hydrogen-bonding network in L-serine crystal
}

\author{
S. Jarmelo ${ }^{\text {a }}$, I. Reva ${ }^{\text {a }}$, P.R. Carey ${ }^{\text {b }}$, R. Fausto ${ }^{\text {a,* }}$ \\ a Department of Chemistry, University of Coimbra, 3004-535 Coimbra, Portugal \\ ${ }^{\mathrm{b}}$ Department of Biochemistry, Case Western Reserve University, 10900 Euclid Ave., Cleveland, OH 44106-4935, USA
}

Received 10 March 2006; received in revised form 24 April 2006; accepted 25 April 2006

Available online 9 June 2006

\begin{abstract}
The IR spectra $\left(4000-400 \mathrm{~cm}^{-1}\right)$ of neat and isotopically substituted (ND/OD $\leq 10 \% \mathrm{D}$ and $\left.\cong 30 \% \mathrm{D}\right)$ polycrystalline L-serine $(\alpha$-amino- $\beta$ hydroxypropionic acid; $\mathrm{HO}-\mathrm{CH}_{2}-\mathrm{CH}\left(\mathrm{NH}_{3}\right)^{+}-\mathrm{COO}^{-}$) were recorded in the temperature range $300-10 \mathrm{~K}$ and assigned. The isotopic-doping/lowtemperature methodology, which allows for decoupling of individual proton vibrational modes from the crystal bulk vibrations, was used for estimating the lengths and energies of the different H-bonds present in L-serine crystal. To this end, the frequency shifts observed in both the $\mathrm{NH} / \mathrm{OH}$ stretching and out-of-plane bending spectral regions (relatively to reference values for these vibrations in non-hydrogen-bonded L-serine molecules) were used, together with previously developed empirical correlations between these spectral parameters and the H-bond properties. In addition, the room-temperature Raman spectrum $\left(4000-150 \mathrm{~cm}^{-1}\right)$ of a single crystal of neat L-serine was also recorded and interpreted. A systematic comparison was made between the spectroscopic data obtained currently for L-serine and previously for DL-serine, revealing that the vibrational spectra of the two crystals reflect well the different characteristics of their hydrogen-bond networks, and also correlate accurately with the different susceptibility of the two crystals to pressure-induced strain.
\end{abstract}

(C) 2006 Elsevier B.V. All rights reserved.

Keywords: L-Serine; H-bonding; Low-temperature IR spectra; Isotopic dilution

\section{Introduction}

The molecular (non-ionic) form of serine was recently studied in our laboratories by low-temperature matrixisolation IR spectroscopy and quantum chemical methods $[1,2]$. In the gas-phase, the monomer of serine was found to exhibit several low energy conformers, which can be grouped accordingly to the dominant intramolecular $\mathrm{H}$-bond they exhibit: A $\left(\mathrm{O}-\mathrm{H}_{\text {Alcohol }} \cdots \mathrm{N}\right)$, B $\left(\mathrm{O}-\mathrm{H}_{\text {Carboxylic }} \cdots \mathrm{N}\right)$ and $\mathrm{C}$ $\left(\mathrm{O}-\mathrm{H}_{\text {Alcohol }} \cdots \mathrm{O}=\right)$. Representatives of $\mathrm{A}, \mathrm{B}$ and $\mathrm{C}$ groups could be trapped in low-temperature argon matrices and subsequently characterized by IR spectroscopy [1]. The importance of entropy on the conformational distribution of serine monomer was also investigated, as well as the photochemistry of this species isolated in the cryogenic matrices [2]. All these studies received support from extensive high-level theoretical calculations $[1,2]$.

\footnotetext{
* Corresponding author. Tel.: +351 919236971; fax: +351 239827703 .

E-mail address: rfausto@ci.uc.pt (R. Fausto).
}

Contrary to the non-ionic form of serine, which has been relatively little studied, its zwitterionic form has been the subject of numerous investigations, since most of the previously reported studies were carried out for the compound in the crystalline phase or in solution. Serine can exist in two enantiomeric modifications, L-serine and D-serine. At the monomer level, the two enantiomers are structurally and spectroscopically identical. However, in the solid state, crystals constructed from the same enantiomer are different from the crystals constructed from the mixture of enantiomers. Very interestingly, DL-serine crystal (including both enantiomers) has been considerably more studied than both L- and D-serine crystals (containing only one enantiomer). For instance, the structure of the DL-crystal was solved for the first time in 1943 [3], while the crystal of L-serine was only reported $c a$. 30 years later (almost simultaneously by three different research groups: first, in 1972, by Benedetti et al. [4], a year later by Ramakumar et al. [5] and, finally, in 1974, by Kistenmacher et al. [6]). The most recent structural study on L-serine crystal was published last year, by Boldyreva et al. [7], who presented a very elegant and detailed discussion on the structure of the crystal, in 
particular pertaining to its hydrogen-bond network and structural changes induced by both cooling and increasing pressure. The crystal was found to be orthorhombic (space group: $P 2{ }_{1} 22_{1}$ ), with four molecules in the unit cell and lattice constants $a=5.615(1) \AA, b=8.589(2) \AA$ and $c=9.346(2) \AA$, at ambient conditions [7]. The crystal is constituted by zwitterions linked via bifurcated intermolecular hydrogen-bonds established between the $-\mathrm{NH}_{3}{ }^{+}$group and the carboxyl moiety of a neighbouring molecule into "head-to-tail" chains along the crystallographic axis $a$. The bifurcated H-bonds are asymmetrical with one short (bond 1) and one long (bond 2) branch. The chains are linked via extra $\mathrm{N}-\mathrm{H} \cdot \mathrm{O}_{\text {Carboxyl }} \mathrm{H}$-bonds into a 3Dnetwork. In one plane $(a \times b)$, the neighbouring chains are antiparallel to each other and are linked by $\mathrm{N}-\mathrm{H} \cdots \mathrm{O}_{\text {Carboxyl }} \mathrm{H}$ bonds parallel to the $b$ axis (bond 3); in the other plane $(a \times c)$, the chains are parallel and connected to one neighbouring chain by $\mathrm{N}-\mathrm{H} \cdots \mathrm{O}_{\text {Carboxyl }} \mathrm{H}$-bonds (bond 4) and to another neighbouring chain by $\mathrm{O}-\mathrm{H} \cdots \mathrm{O}$ bonds established between the $-\mathrm{CH}_{2} \mathrm{OH}$ side groups (bond 5). There are four labile protons in the zwitterions. Those belonging to the ammonium group are involved in considerably strong hydrogen-bonds, the $\mathrm{H}$-bond distances being $2.8700(19) \AA / 3.1116(18) \AA$ (short and long branch of the bifurcated H-bond, respectively), 2.874(2) $\AA$ (bond 3) and 2.841(2) $\AA$ (bond 4), at room temperature [7]. Somewhat surprisingly, the $\mathrm{O}-\mathrm{H}$. . O intermolecular H-bonds between neighbouring chains (bond 5) were found to be relatively weak, the H-bond distance being 2.9181(8) $\AA$ [7].

Compared to the racemic DL-serine crystal [8], the crystal of enantiomeric L-serine was found to be considerably more susceptible to pressure-induced changes, exhibiting phase transitions at about 5 and $8 \mathrm{GPa}$, while for the first crystal no pressure-induced phase transition could be observed until at least $8.6 \mathrm{GPa}[9,10]$. This behaviour could be thought to be an indication of more compact packing in the crystal of DL-serine, relatively to L-serine. However, just the opposite happens: at ambient conditions, the density of L-serine $\left(1.549 \mathrm{~g} / \mathrm{cm}^{3}\right)$ is higher than that of DL-serine $\left(1.531 \mathrm{~g} / \mathrm{cm}^{3}\right)$. In fact, there is accumulated evidence that the different properties of the two crystals are essentially due to the different interactions established by the $-\mathrm{CH}_{2} \mathrm{OH}$ side groups in each case [7-9]. The most relevant piece of information supporting this idea is the fact that, after the pressure-induced phase transition, the $\mathrm{O}-\mathrm{H} \cdots \mathrm{O}_{\text {Alcohol }} \mathrm{H}$-bond is substituted by the presumably stronger $\mathrm{O}-\mathrm{H} \cdots \mathrm{O}_{\text {Carboxyl }} \mathrm{H}$-bond, while all the remaining $\mathrm{H}$-bonds are kept without any strong structural changes [8,9]. In addition, it was also found that the most important changes in other structural parameters (in particular, bond and dihedral angles) occurring upon increase of pressure do also take place in the $-\mathrm{CH}_{2} \mathrm{OH}$ groups [8,9]. Furthermore, the most important differences between the structures of the zwitterionic units in the crystals of L-serine and DL-serine were also observed for the $-\mathrm{CH}_{2} \mathrm{OH}$ related parameters [8]. Since infrared spectroscopy is a technique particularly sensitive to vibrations originating in highly polarized groups, such as the $\mathrm{OH}$ moiety, one could expect that its use to the study of the specificities of the H-bond network in serine crystals might be able to further improve our knowledge on these systems.
The room-temperature vibrational spectra (IR and Raman) of the crystal of L-serine have been reported for the first time, in 1973, by Krishnan et al. [11]. Six years later, Madec et al. [12] extended the analysis of the vibrational spectra of L-serine to its deuterated isotopologue, $\mathrm{L}-$ serine- $\mathrm{D}_{4}\left[\mathrm{DO}-\mathrm{CH}_{2}-\mathrm{CH}\left(\mathrm{ND}_{3}\right)^{+}-\right.$ $\mathrm{COO}^{-}$]. The far-IR spectrum of $\mathrm{L}$-serine was recorded by Husain et al. [13] and, more recently, by Korter et al. [14]. In addition, the inelastic incoherent neutron scattering (IINS) spectra were also obtained at $10 \mathrm{~K}$ for neat $\mathrm{L}$-serine and L-serine- $\mathrm{D}_{4}$ by Pawlukojć et al. [15]. However, none of these studies investigated the details of the spectral regions where the proton modes absorb, in particular the high frequency range $\left(>2000 \mathrm{~cm}^{-1}\right)$, since under the experimental conditions used the $\nu \mathrm{O}-\mathrm{H}$ and $\nu \mathrm{N}-\mathrm{H}$ vibrations give rise to a very broad and extensively structured spectral feature, not allowing direct identification of the bands due to individual modes.

The theoretical study of the zwitterionic monomeric form of L-serine has also been attempted in the past. Pawlukojć et al. [15] have used $a b$ initio (HF and MP2) and DFT/B3LYP methods with $6-31 \mathrm{G}(\mathrm{d})$ and $6-311++\mathrm{G}(\mathrm{d}, \mathrm{p})$ basis sets to investigate this system. However, both the DFT and MP2 calculations failed to retain the zwitterionic structure. After optimisation, the structures converged to the neutral (molecular) form of serine. Indeed, it is well known that the zwitterionic forms of simple amino acids in general do not correspond to true minima in the potential energy surface (PES) of the isolated monomer, optimisation to minimum energy structures systematically converging to the molecular species (as observed in the present case). This was found, for instance, for glycine [16,17], and $\alpha$ - and $\beta$-alanine [18]. However, it is also well known that, contrarily to more sophisticated methods, low-level Hartree-Fock calculations in general predict the isolated zwitterionic forms of simple amino acids as being minima on the corresponding PES $[19,20]$. This is nowadays known to be an erroneous prediction of such low-level calculations, but it has the advantage of enabling theoretical predictions of vibrational spectra (among studied properties that are only meaningful when calculated for stationary points on the PES) to be made. Since vibrational spectra (in particular vibrational frequencies) are in general predicted well enough even at low theoretical level for most of practical applications (e.g., general spectra assignment), use of properly scaled vibrational frequencies obtained using low-level theoretical $a b$ initio calculations to help in the interpretation of experimental spectra of zwitterionic species has been considered frequently in the past. For instance, Pawlukojć et al. [15] attempted to use this approach to predict the vibrational frequencies of serine and compare them with the IINS experimental spectrum obtained for the crystal. In this case, the comparison was not, however, particularly favourable. Several theoretical studies were also reported dealing with serine in solution, which simulated the solvent as a continuum media characterized by its dielectric constant [21-26] or, alternatively, considered explicitly a few solvent molecules, which were found to be required for stabilization of the zwitterions [27-29].

As a whole, both the experimental and theoretical results previously obtained for L-serine stress the importance of a 
detailed structural and vibrational characterization of this amino acid in the crystalline phase.

In the present investigation, IR spectroscopy was applied to the study of crystals of L-serine with natural isotopic abundance and partially deuterated ( $\leq 10$ and $\cong 30 \%$ deuterium content) within the temperature range $300-10 \mathrm{~K}$. In the case of the deuterium-doped crystals, the minority deuterated molecules are well isolated within the non-deuterated crystal bulk and their deuterium-related vibrations are not affected by symmetry-related interactions and local anisotropy resulting from thermal excitation. For non-doped crystals, these interactions usually lead to a strong broadening of the vibrational bands originated in the hydrogen-bonded groups and prevent observation of their characteristic temperature dependence [30-32]. On the other hand, the widths of the bands associated with the decoupled vibrations given rise by the minority deuterated molecules present in the doped crystals are much smaller. It is then possible, working under low-temperature conditions, to increase further the spectral resolution of the vibrational spectra, and allow for the observation of protonrelated bands ascribable to specific $\mathrm{H}$-bonds in the crystal. This isotopic-doping/low-temperature methodology was previously applied successfully to the study of H-bonding in the crystals of many biologically relevant systems, including DL-serine [33], and led to the establishment of very general correlations between the frequency shifts of the proton stretching and outof-plane bending vibrations occurring upon $\mathrm{H}$-bond formation and the corresponding H-bond lengths and energies [34-38]. Such correlations were also used in this study to estimate $\mathrm{H}$-bond properties in the L-serine crystal from the measured spectroscopic data.

\section{Materials and methods}

L-Serine was obtained commercially (spectroscopic grade) from Sigma and used without any additional purification.

The IR spectra of polycrystalline natural isotopic abundance $(\mathrm{NH} / \mathrm{OH} \cong 100 \% \mathrm{H})$ and partially deuterated (ND/OD $\leq 10 \%$ $\mathrm{D}$ and $\cong 30 \% \mathrm{D})$ crystals of L-serine in a $\mathrm{KBr}$ (1:200) pellet, attached to the cold finger of an APD Cryogenics closed-cycle helium refrigeration system with a DE-202A expander, were recorded using a Mattson Infinity 60AR series FTIR spectrometer, with spectral resolution $1 \mathrm{~cm}^{-1}$. The temperature (300$10 \mathrm{~K}$ ) was measured directly at the sample holder by a silicon diode temperature sensor connected to a Scientific Instruments temperature controller (model 9650). The sample temperature during registration of spectra was stabilized to $c a$. $\pm 0.2 \mathrm{~K}$. The temperature-induced spectral changes observed for both substances were found to be reversible and highly reproducible. The deuterated samples were obtained from commercial L-serine by recrystallization from the solution in $\mathrm{D}_{2} \mathrm{O}$ (Aldrich).

Raman spectra were obtained using the $647.1 \mathrm{~nm}$ laser excitation from an Innova 400 Krypton Laser System (Coherent, Inc.), a back-illuminated charge-couple device (CCD) detector (model 1024EHRB/1, Princeton Instruments, Inc.) operating at $183 \mathrm{~K}$, and a Holospec $f / 1.4$ axial transmission spectrometer (Kaiser Optical Systems, Inc.) employed as a single mono- chromator [39]. The Raman laser probe was focused on the single crystal of L-serine with help of a microscope [40].

The hanging drop vapor diffusion technique was successfully applied to grow up the single crystal of L-serine (conditions - sample solution: aqueous solution of L-serine (400 mg/mL; $T \cong 325 \mathrm{~K}$ ); reservoir: $1 \mathrm{~mL}$ of $1.663 \mathrm{M}$ of $\mathrm{NaCl}$ solution; hanging drop: $4 \mu \mathrm{L}$ sample solution).

\section{Results and discussion}

To follow the same nomenclature adopted in our previous study on the crystal of DL-serine [33], the three presently studied samples of L-serine will be abbreviated by Ser (L-serine crystal with natural isotopic abundance), Ser90 ( $\leq 10 \% \mathrm{D} ; \geq 90 \% \mathrm{H}$ ) and $\operatorname{Ser} 70$ ( $\cong 30 \% \mathrm{D} ; \cong 70 \% \mathrm{H}$ ). In the following sections, discussion will be centred on the spectra obtained for Ser and Ser70. The spectra of Ser90 were found identical to those of Ser70 (except in what concerns to intensities of the deuteriumrelated bands), showing that in both samples the deuterated molecules can be considered sufficiently well isolated.

The observed IR spectra of polycrystalline Ser and Ser70, at room temperature and at $10 \mathrm{~K}$, are presented in Figs. $1-3$. The observed Raman spectrum of Ser single crystal, at room temperature, is presented in Fig. 4. The proposed band assignments are given in Table 1.

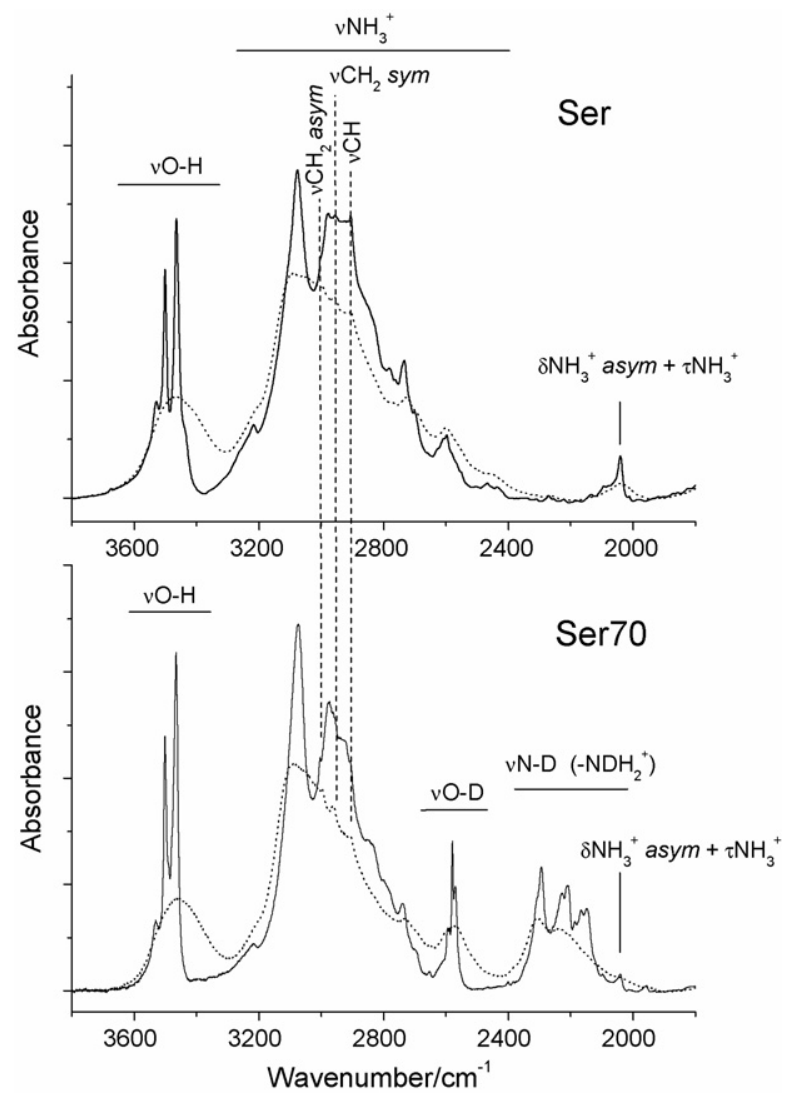

Fig. 1. The $3800-1800 \mathrm{~cm}^{-1}$ range of the IR spectra of polycrystalline Ser and Ser70 at room ( $300 \mathrm{~K}$; dotted line) and low (10 K; solid line) temperatures. Vertical dashed lines indicate the position of the methylene and methyne stretching vibrations. 

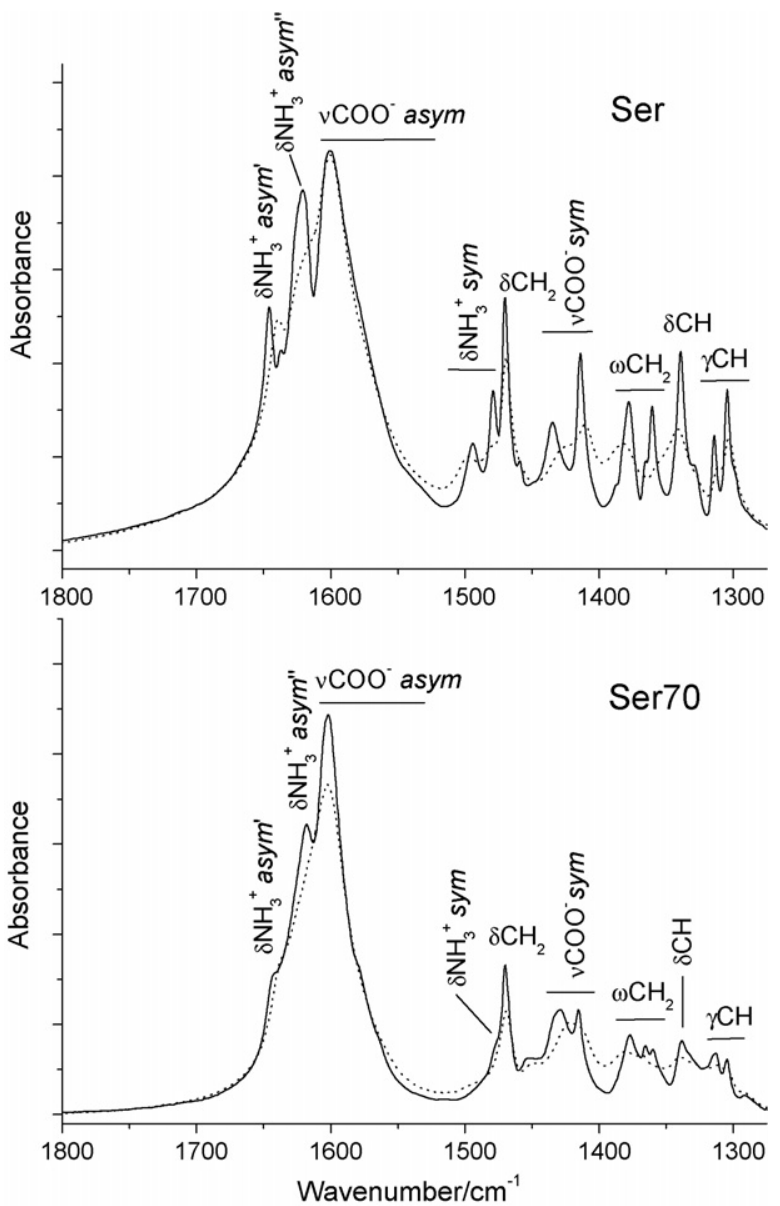

Fig. 2. The $1800-1275 \mathrm{~cm}^{-1}$ range of the IR spectra of polycrystalline Ser and Ser70 at room ( $300 \mathrm{~K}$; dotted line) and low (10 K; solid line) temperatures.

To facilitate the analysis of the vibrational data, the discussion of the experimental results will be made dividing the spectra in three regions. Band positions in the IR spectra quoted during discussion will correspond to the positions of absorption peaks for the samples cooled to $10 \mathrm{~K}$.

\subsection{The 4000-1800 $\mathrm{cm}^{-1}$ spectral range (Figs. 1 and 4)}

Bands due to the stretching vibrations of hydroxyl [OH(D)], ammonium $\left[\mathrm{NH}(\mathrm{D})_{3}{ }^{+}\right]$, methylene $\left(\mathrm{CH}_{2}\right)$ and methyne $(\mathrm{CH})$ groups are expected to be observed in the $3800-1800 \mathrm{~cm}^{-1}$ spectral range.

In this spectral range, the room-temperature IR spectra of Ser, Ser90 and Ser70 polycrystalline samples present the expected broad and structured shape typical of amino acids $[18,33]$. This behaviour is illustrated in Fig. 1, where the IR spectra of Ser and Ser70 are shown. The overlapping signals become progressively narrower and the peak intensities increase considerably on cooling, leading to the observation of more pronounced band structure at low temperature. The characteristically narrow bands due to the $\mathrm{CH}$ stretching vibrations ( $\nu \mathrm{CH}_{2}$ asym, $\nu \mathrm{CH}_{2}$ sym and $\left.\nu \mathrm{CH}\right)$ can then be picked up easier from the broad profile; they correspond to the maxima at $3004 \mathrm{~cm}^{-1}\left(\nu \mathrm{CH}_{2}\right.$ asym $), 2956 \mathrm{~cm}^{-1}\left(\nu \mathrm{CH}_{2}\right.$ sym $)$ and

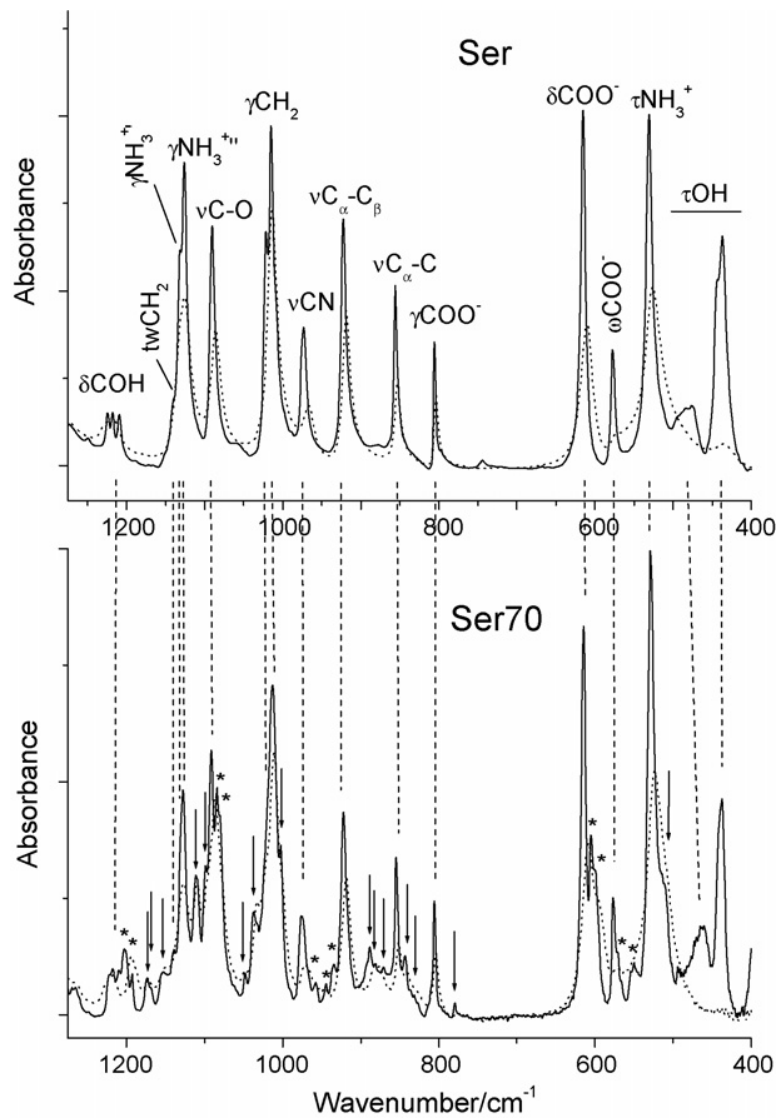

Fig. 3. The $1275-400 \mathrm{~cm}^{-1}$ range of the IR spectra of polycrystalline Ser and Ser70 at room ( $300 \mathrm{~K}$; dotted line) and low $(10 \mathrm{~K}$; solid line) temperatures. In the spectra of Ser70, the arrows indicate the positions of the uncoupled bands of deuterated groups and the asterisks the satellite bands of bands mainly due to vibrations of other groups, but noticeably shifted by deuteration. The vertical dashed lines indicate the main common bands in the two spectra and are included to facilitate their comparison.

$2905 \mathrm{~cm}^{-1}$ ( $\left.\nu \mathrm{CH}\right)$ (Fig. 1 and Table 1). These bands relate to the sharp bands at 2989, 2955 and $2903 \mathrm{~cm}^{-1}$ in the roomtemperature Raman spectrum of the single crystal of Ser (Fig. 4). Regarding these vibrations, our assignments agree with those of Pawlukojć et al. [15].

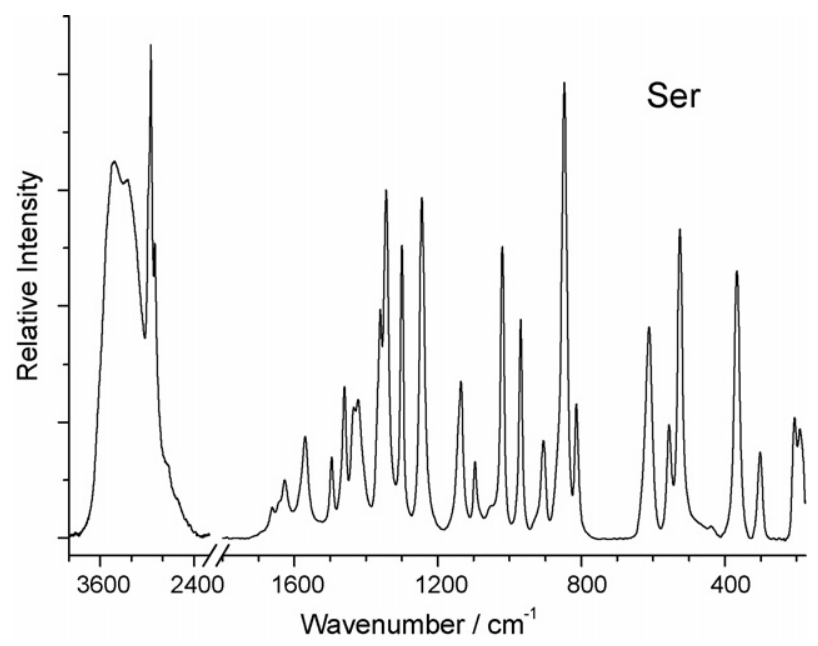

Fig. 4. Room-temperature Raman spectrum of a single crystal of Ser. 
Table 1

Peak frequencies $\left(\mathrm{cm}^{-1}\right)$, qualitative intensities ${ }^{\mathrm{a}}$ and assignment of bands of the IR spectra of neat (Ser) and isotopically diluted (Ser90 and Ser70) L-serine polycrystalline samples at $10 \mathrm{~K}$, in the range $4000-400 \mathrm{~cm}^{-1}$, and of the Raman spectrum of neat (Ser) L-serine single crystal at $300 \mathrm{~K}$, in the range $4000-150 \mathrm{~cm}^{-1}$

\begin{tabular}{|c|c|c|c|}
\hline \multirow[t]{2}{*}{ Assignment $^{\mathrm{b}}$} & \multicolumn{2}{|l|}{ IR } & \multirow{2}{*}{$\begin{array}{l}\text { Raman } \\
\text { Ser }\end{array}$} \\
\hline & $\overline{\text { Ser }}$ & Ser90/Ser70 & \\
\hline$\overline{\mathrm{\nu OH}}$ & $\begin{array}{l}3529(\mathrm{~m}) \\
3501(\mathrm{~s}) \\
3465(\mathrm{vs})\end{array}$ & & 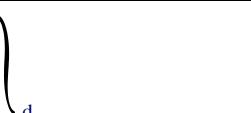 \\
\hline$\nu \mathrm{NH}_{3}{ }^{+}$asym $^{\prime \prime}$ & 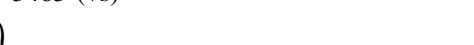 & & $d$ \\
\hline $\begin{array}{l}\nu \mathrm{NH}_{3}^{+}{ }^{+} \text {asym }^{\prime} \\
\nu \mathrm{NH}_{3}{ }^{+} \mathrm{sym}\end{array}$ & $3350-2500$ & & \\
\hline$\nu \mathrm{CH}_{2}$ asym & 3004 (vs) & & $2989(\mathrm{sh})$ \\
\hline$\nu \mathrm{CH}_{2} \mathrm{sym}$ & 2956 (vs) & & 2955 (vs) \\
\hline$\nu \mathrm{CH}$ & 2905 (vs) & & $2903(\mathrm{~s})$ \\
\hline$\nu \mathrm{O}-\mathrm{D}$ & & $2595(\mathrm{~m}), \mathbf{2 5 8 9}(\mathrm{m}), \mathbf{2 5 8 0}(\mathrm{s}), \mathbf{2 5 7 0}(\mathrm{s})$ & \\
\hline$\nu \mathrm{N}-\mathrm{D}\left(\right.$ in $\left.-\mathrm{NDH}_{2}^{+}\right)($bond 3 ) & & $2346(\mathrm{sh}), 2308(\mathrm{sh}), 2294(\mathrm{~m})$ & \\
\hline$\nu \mathrm{N}-\mathrm{D}\left(\right.$ in $\left.-\mathrm{NDH}_{2}^{+}\right)($bond 4$)$ & & $2258(\mathrm{sh}), 2229(\mathrm{~s}), 2211(\mathrm{~s})$ & \\
\hline $\begin{array}{l}\nu \mathrm{N}-\mathrm{D} \text { (in }-\mathrm{NDH}_{2}^{+} \text {) } \\
\quad \text { (bifurcated hydrogen-bond) }\end{array}$ & & $2188(\mathrm{~m}), 2167(\mathrm{~m}), 2148(\mathrm{~m})$ & \\
\hline$\delta \mathrm{NH}_{3}^{+}$asym $^{\prime}$ & $1646(\mathrm{~s}), 1637(\mathrm{sh})$ & & $1662(\mathrm{w}), 1644(\mathrm{sh})$ \\
\hline$\delta \mathrm{NH}_{3}{ }^{+}$asym $^{\prime \prime}$ & 1621 (vs) & & $1627(w)$ \\
\hline$\nu \mathrm{COO}^{-}$asym & 1601 (vs), 1580 (sh) & & $1571(\mathrm{~m}), 1585(\mathrm{sh})$ \\
\hline$\delta \mathrm{NH}_{3}{ }^{+} \mathrm{sym}$ & $1494(\mathrm{~m}), 1479(\mathrm{~m})$ & & $1496(\mathrm{~m})$ \\
\hline$\delta \mathrm{CH}_{2}$ & $1470(\mathrm{~s}), 1459(\mathrm{~m})$ & & $1461(\mathrm{~m})$ \\
\hline$\nu \mathrm{COO}^{-}$sym & $1434(\mathrm{~s}), 1414(\mathrm{~s})$ & & $1434(\mathrm{~m}), 1423(\mathrm{~m})$ \\
\hline$\omega \mathrm{CH}_{2}$ & $1387(\mathrm{sh}), 1378(\mathrm{~s}), 1365(\mathrm{sh}), 1361(\mathrm{~s})$ & & $1361(\mathrm{~m})$ \\
\hline$\delta \mathrm{CH}$ & $1339(\mathrm{~s}), 1330(\mathrm{sh})$ & & $1345(\mathrm{~s})$ \\
\hline$\gamma \mathrm{CH}$ & $1314(\mathrm{~m}), 1305(\mathrm{~s}), 1300(\mathrm{sh})$ & & $1301(\mathrm{~s})$ \\
\hline$\delta \mathrm{COH}$ & $1224(w), 1218(w), 1209(w)$ & $1202(w), 1200(w), 1193(w)$ & $1245(\mathrm{~s})$ \\
\hline $\begin{array}{l}\delta \mathrm{N}-\mathrm{D} \text { (in }-\mathrm{NDH}_{2}^{+} \text {) } \\
\quad \text { (bifurcated hydrogen-bond) }\end{array}$ & & $1173(\mathrm{~m}), \mathbf{1 1 7 0}(\mathrm{sh}), \mathbf{1 1 5 3}(\mathrm{m})$ & \\
\hline $\mathrm{twCH}_{2}$ & $1140(\mathrm{sh})$ & & $1143(\mathrm{sh})$ \\
\hline$\gamma \mathrm{NH}_{3}^{+\prime}$ & $1132(\mathrm{~s})$ & & $1137(\mathrm{~m})$ \\
\hline$\gamma \mathrm{NH}_{3}{ }^{+\prime \prime}$ & $1126(\mathrm{~s})$ & & \}$^{113} /(\mathrm{m})$ \\
\hline$\delta \mathrm{N}-\mathrm{D}\left(\right.$ in $\left.-\mathrm{NDH}_{2}^{+}\right)($bond 4$)$ & & $1111(\mathrm{~s}), 1098(\mathrm{sh})$ & \\
\hline$\nu \mathrm{CO}$ & $1090(\mathrm{~s})$ & $1084(\mathrm{~m}), 1081(\mathrm{~m})$ & $1097(\mathrm{~m})$ \\
\hline$\delta \mathrm{N}-\mathrm{D}\left(\right.$ in $\left.-\mathrm{NDH}_{2}^{+}\right)($bond 3 ) & & $1048(\mathrm{~s}), 1038(\mathrm{sh})$ & \\
\hline$\gamma \mathrm{CH}_{2}$ & $1022(\mathrm{~s}), 1015(\mathrm{~s})$ & $1004(\mathrm{sh})$ & $1053(\mathrm{sh}), 1021$ (s) \\
\hline$\nu \mathrm{CN}$ & $973(\mathrm{~m})$ & $958(w)$ & $969(\mathrm{~m})$ \\
\hline$\nu \mathrm{C}_{\alpha}-\mathrm{C}_{\beta}$ & $922(\mathrm{~s})$ & $945(w), 935(w)$ & $906(\mathrm{~m})$ \\
\hline$\delta \mathrm{COD}$ & & $888(\mathrm{~m}), \mathbf{8 8 1}(\mathrm{m}), \mathbf{8 7 0}(\mathrm{m})$ & \\
\hline$\nu \mathrm{C}_{\alpha}-\mathrm{C}$ & $856(\mathrm{~s})$ & & $848(\mathrm{~s})$ \\
\hline $\begin{array}{l}\gamma \mathrm{N}-\mathrm{D}\left(\text { in }-\mathrm{NDH}_{2}^{+}\right) \\
\quad \text { (bifurcated hydrogen-bond) }\end{array}$ & & $844(\mathrm{~m})$ & \\
\hline$\gamma \mathrm{COO}^{-}$ & 806 (m), 796 (sh) & & $814(\mathrm{~m}), 770(\mathrm{w})$ \\
\hline$\gamma \mathrm{N}-\mathrm{D}\left(\right.$ in $\left.-\mathrm{NDH}_{2}^{+}\right)($bond 4$)$ & & $819(\mathrm{vw})$ & \\
\hline$\gamma \mathrm{N}-\mathrm{D}\left(\right.$ in $\left.-\mathrm{NDH}_{2}^{+}\right)($bond 3 ) & & $780(\mathrm{~m})$ & \\
\hline $8 \mathrm{COO}^{-}$ & $616(\mathrm{~s})$ & $605(\mathrm{~m}), 600(\mathrm{sh})$ & $611(\mathrm{~m})$ \\
\hline$\omega \mathrm{COO}^{-}$ & $577(\mathrm{~m})$ & $570(\mathrm{sh}), 554(\mathrm{w})$ & $557(\mathrm{~m})$ \\
\hline$\tau \mathrm{NH}_{3}^{+}$ & $531(\mathrm{~s})$ & & $526(\mathrm{~s})$ \\
\hline$\tau \mathrm{NDH}_{2}^{+}$ & & $513(\mathrm{sh})$ & \\
\hline$\tau \mathrm{OH}$ & $476(\mathrm{w}), 444(\mathrm{sh}), 437(\mathrm{~s})$ & $462(w)^{e}$ & $438(w)$ \\
\hline$\delta \mathrm{CCC}$ & n.i. & & ) \\
\hline$\rho \mathrm{CCC}$ & n.i. & & $368(\mathrm{~s}), 303(\mathrm{~m})$ \\
\hline$\delta \mathrm{CC}_{\alpha} \mathrm{N}$ & n.i. & & \\
\hline$\rho \mathrm{COO}^{-}$ & n.i. & & $205(\mathrm{sh}), 184(\mathrm{~s})$ \\
\hline
\end{tabular}

a vs, very strong; s, strong; m, medium; w, weak; vw, very weak; sh, shoulder.

b $\nu$, bond stretching; $\delta$, bending; $\omega$, wagging; $\gamma$, rocking (out-of-plane); tw, twisting; $\tau$, torsion; asym, anti-symmetric; sym, symmetric; n.i., not investigated.

${ }^{\mathrm{c}}$ In this column we provide only the frequencies of the bands which are absent in the spectra of Ser and are due to (i) uncoupled vibrations of deuterated groups (frequencies presented in bold), and (ii) satellite bands of bands mainly due to vibrations of other groups, but noticeably shifted by deuteration.

${ }^{\mathrm{d}}$ The $\nu \mathrm{OH}$ and $\mathrm{\nu NH}_{3}{ }^{+}$modes give rise to an intense feature extended from $c a .3700$ to $2500 \mathrm{~cm}^{-1}$, with main maxima at 3446 and $3250 \mathrm{~cm}^{-1}$.

e This frequency does not correspond to a satellite band absent in the spectra of Ser, but it corresponds to the frequency in the spectra of Ser90 and Ser70 of the band observed in Ser at $476 \mathrm{~cm}^{-1}$ (see text for discussion). 
The $\mathrm{OH}$ stretching mode gives rise to the features observed in the $3550-3350 \mathrm{~cm}^{-1}$ range. In the infrared spectra obtained at low temperature, a multiplet of bands is observed in this spectral region, with main maxima at 3529, 3501 and $3465 \mathrm{~cm}^{-1}$ (Fig. 1 and Table 1). Observation of this multiplet structure results from non-equivalence of monomeric units in the crystalline unitary cell and vibrational coupling between different molecules (crystal field splitting), the same behaviour being also observed in other spectral regions (in particular for $\delta \mathrm{COH}$ and $\tau \mathrm{OH}$ modes), as it will be discussed in detail later on. In the room-temperature spectra, $\nu \mathrm{OH}$ appears as a broad unstructured band with maximum at $3462 \mathrm{~cm}^{-1}$ (infrared) or at $3446 \mathrm{~cm}^{-1}$ (in the Raman spectrum).

It is very interesting to compare the relative position of the bands ascribed to $\mathrm{\nu OH}$ in the crystals of $\mathrm{L}-$ and DL-serine, since this is a spectral parameter that clearly reflects the different packing in the two crystals. As mentioned in Section 1, in the crystal of $\mathrm{L}$-serine the $\mathrm{O}-\mathrm{H} \cdots \mathrm{O}_{\text {Alcohol }}$ intermolecular $\mathrm{H}$-bonds between neighbouring chains (bond 5) were found to be relatively weak, the H-bond distance being 2.9181(8) $\AA$ [7]. On the other hand, in the crystal of DL-serine, the $-\mathrm{CH}_{2} \mathrm{OH}$ group is hydrogen-bonded to the carboxylic group of a neighboured molecule $[8,41]$ (as in the high-pressure polymorph of L-serine) $[7,8]$. This $\mathrm{O}-\mathrm{H} \cdots \mathrm{O}_{\text {Carboxyl }}$ intermolecular $\mathrm{H}$-bond is considerably stronger than the $\mathrm{O}-\mathrm{H} \cdots \mathrm{O}_{\text {Alcohol }} \mathrm{H}$-bond in L-serine crystal, as reflected by the corresponding $\mathrm{H}$-bond distance: $2.671 \AA$ [41]. Accordingly, the absorption bands due to the $\mathrm{vOH}$ mode of L-serine are observed at much higher-frequency than in the spectrum of DL-serine, where they are observed at $c a$. $2900 \mathrm{~cm}^{-1}$ (superimposed with the $\nu \mathrm{NH}$ and $\nu \mathrm{CH}$ stretching modes [33]).

The $\mathrm{vNH}_{3}{ }^{+}$modes give rise to bands in the $3350-2500 \mathrm{~cm}^{-1}$ range. As usually, these bands are intense, but also very broad and complex, as a result of anharmonic coupling with low frequency modes, which precludes the assignment of the bands to a particular vibration.

In the $2650-1800 \mathrm{~cm}^{-1}$ region, there are no prominent bands in the spectra of Ser. The most intense band in this range is observed at $c a$. $2040 \mathrm{~cm}^{-1}$. This band could be easily assigned to the $\left(\delta \mathrm{NH}_{3}{ }^{+}\right.$asym $\left.+\tau \mathrm{NH}_{3}{ }^{+}\right)$combination, which is a well-known feature appearing in the infrared spectra of crystalline amino acids $[33,42]$. On the other hand, in the spectra of the deuterium-doped crystals (Ser70 and Ser90), the $2650-1800 \mathrm{~cm}^{-1}$ region is the spectral range where the bands due to the uncoupled ND and OD stretching vibrations of the minority deuterated molecules are observed. As already mentioned, according to the crystalline structure of L-serine [7], the three ammonium hydrogen atoms are involved in different H-bonds. Then, three bands (or groups of bands) should be observed in this spectral region due to molecules containing the $-\mathrm{NDH}_{2}{ }^{+}$group. In addition, -OD containing molecules should also give rise to a band (or group of bands) in this spectral range.

As shown in Fig. 1, in the low-temperature spectrum of Ser70 the bands due to the uncoupled deuteron stretching vibrations of both the $-\mathrm{NDH}_{2}{ }^{+}$and -OD groups are easily identifiable: $\nu \mathrm{O}-\mathrm{D}$ gives rise to a multiplet with maxima at
2595, 2589, 2580 and $2570 \mathrm{~cm}^{-1}$, exhibiting a profile quite similar to that corresponding to the $v \mathrm{O}-\mathrm{H}$ feature, while the $\nu \mathrm{N}-\mathrm{D}$ modes give rise to three triplets of bands at 2346/2308/ 2294, 2258/2229/2211 and 2188/2167/2148 $\mathrm{cm}^{-1}$ (see also Table 1). As expected, all these bands exhibit marked temperature dependence.

The assignment of the $v \mathrm{~N}-\mathrm{D}$ bands to a specific $\mathrm{N}-\mathrm{D}$ linkage can be made taking into consideration the different strengths of the three $\mathrm{N}-\mathrm{D} \cdots \mathrm{O}_{\text {Carboxyl }} \mathrm{H}$-bonds in the L-serine crystal, as reflected by the corresponding H-bond distances. However, it must be noticed that, according to the structural data [4-7], the $\mathrm{H}$-bond angles $\left(\mathrm{N}-\mathrm{H} \cdots \mathrm{O}_{\text {Carboxyl }}\right)$ are different in the three $\mathrm{H}$-bonds. Hence, the $\mathrm{N} \cdots \mathrm{O}$ distances are not the best parameter to be correlated with frequencies, which indeed depend mainly on the distances involving the hydrogen atoms. Very unfortunately, the available structural information on these distances is inconsistent, due to the well-known difficulty of Xray diffraction experiments to localize precisely hydrogen atoms (in particular when they are involved in hydrogenbonds). Just to give an example, for the hydrogen-bond 4, the $\mathrm{H} \cdots \mathrm{O}$ distance reported in refs $[4,6,7]$ is 2.01(3), 1.91(4) and $1.889 \AA$, respectively. In any case, the analysis of the three sets of structural data previously reported $[4,6,7]$ enabled us to conclude that bond 3 (linking the antiparallel chains in the $a \times b$ plane) is the weakest $\mathrm{N}-\mathrm{H} \cdots \mathrm{O}_{\text {Carboxyl }}$ bond in the L-serine crystal (average measured $\mathrm{H} \cdots \mathrm{O}$ distance, $1.957 \AA$ ), while bond 1 (associated with the shortest branch of the bifurcated hydrogen-bond) and bond 4 (linking the chains parallelely in the $a \times c$ plane) have nearly the same strength (average $\mathrm{H} \cdots \mathrm{O}$ distances are 1.934 and $1.936 \AA$, respectively). However, due to the presence of the second component of the bifurcated hydrogen-bond, it can be considered that as a whole the bifurcated H-bond will indeed be the strongest hydrogenbond in the $\mathrm{L}$-serine crystal. Then, the three observed triplets of bands associated with the uncoupled $\nu \mathrm{N}-\mathrm{D}$ vibrations in deuterium-doped serine crystals can be assigned, in a descending order of their frequency, to bond 3, bond 4 and the bifurcated bond, respectively.

It is also worth noticing that the observed frequencies of the uncoupled deuterons of the $-\mathrm{NDH}_{2}{ }^{+}$group in the crystals of L-serine and DL-serine are very similar: 2316, 2232 and $2167 \mathrm{~cm}^{-1}$ (mean values), for L-serine, compared to 2293, 2232 and $2197 \mathrm{~cm}^{-1}$, for DL-serine [33]. These results clearly indicate that the key difference in the hydrogen-bond networks of the two crystals is associated with their distinct $\mathrm{O}-\mathrm{H} \cdots \mathrm{O}$ interactions, as was already suggested by the structural data and, in particular, by the pressure-induced structural changes observed by Boldyreva et al. $[7,8,10]$.

\subsection{The $1800-1275 \mathrm{~cm}^{-1}$ spectral range (Figs. 2 and 4)}

Bands due to the stretching modes of the carboxylate group $\left(\nu \mathrm{COO}^{-}\right.$asym and $\nu \mathrm{COO}^{-}$sym) and to the bending modes of the ammonium group $\left(\delta \mathrm{NH}_{3}{ }^{+}\right.$asym ${ }^{\prime}, \delta \mathrm{NH}_{3}{ }^{+}$asym ${ }^{\prime \prime}$ and $\delta \mathrm{NH}_{3}{ }^{+}$ sym) are expected to appear in this spectral region. In addition, the scissoring and wagging modes of the $-\mathrm{CH}_{2}$ group, as well as the two bending modes of the $-\mathrm{CH}$ fragment $(\delta \mathrm{CH}$ and $\gamma \mathrm{CH})$ 
should also give rise to bands in this spectral region. As shown in Fig. 2, most of the bands observed in this spectral range show multiple components, resulting from crystal field splitting or anharmonic couplings (especially at low temperature; in some cases, at higher-temperatures the increased bandwidths preclude clear observation of the different band components).

The $\delta \mathrm{NH}_{3}{ }^{+}$asym ${ }^{\prime}, \delta \mathrm{NH}_{3}{ }^{+}$asym ${ }^{\prime \prime}$ and $\delta \mathrm{NH}_{3}{ }^{+}$sym modes are assigned to features around 1645,1620 and $1490 \mathrm{~cm}^{-1}$, respectively, which exhibit strong temperature dependence and reduce noticeably their intensity in the spectra of the deuteriumdoped crystals (see Fig. 2). In the Raman spectrum of Ser at room temperature, the $\delta \mathrm{NH}_{3}{ }^{+}$asym ${ }^{\prime}$ and $\delta \mathrm{NH}_{3}{ }^{+}$asym ${ }^{\prime \prime}$ modes are assigned to features at $1662 / 1644$ and $1627 \mathrm{~cm}^{-1}$, while $\delta \mathrm{NH}_{3}{ }^{+}$sym is assigned to the band at $1496 \mathrm{~cm}^{-1}$ (Fig. 4).

The assignment of the bands due to the two carboxylate stretching modes is straightforward. It has been pointed out that the $\mathrm{\nu COO}^{-}$anti-symmetric stretching mode shows a large sensitivity to crystal field effects [43] becoming very intense and spreading through a wide spectral region. Hence, the broad intense band with main maximum at $c a .1600 \mathrm{~cm}^{-1}$ was assigned to this vibration, which has correspondence in the Raman spectrum with the band observed at $1571 \mathrm{~cm}^{-1}$ (with shoulder at $1585 \mathrm{~cm}^{-1}$ ). In turn, the $\nu \mathrm{COO}^{-}$symmetric mode is assigned to the doublet of bands at 1434 and $1414 \mathrm{~cm}^{-1}$, which have counterparts at 1434 and $1423 \mathrm{~cm}^{-1}$ in the Raman spectrum. The assignments of the carboxylate modes clearly follow those previously made for the crystal of DL-serine, though in the latter crystal the $\nu \mathrm{COO}^{-}$symmetric mode gives rise to a multiplet of bands due to involvement in a Fermi resonance interaction with the first overtone of the $\mathrm{OH}$ torsion [33]. Because the hydrogen-bond involving the $\mathrm{OH}$ moiety in $\mathrm{L}$-serine is much weaker than in the DL-serine crystal, $\tau \mathrm{OH}$ has a considerably lower-frequency in L-serine $\left(c a .450 \mathrm{~cm}^{-1}\right)$ than in DL-serine $\left(744 \mathrm{~cm}^{-1}\right.$ [33]) and the Fermi resonance cannot take place in this case.

The $\delta \mathrm{CH}_{2}$ and $\omega \mathrm{CH}_{2}$ vibrations as well as the two bending modes due to the methyne group $(\delta \mathrm{CH}$ and $\gamma \mathrm{CH})$ give rise to bands at nearly the same positions as in the DL-serine crystal. They are assigned: $\delta \mathrm{CH}_{2}$ to the doublet at $1470 / 1459 \mathrm{~cm}^{-1}$ $\left(1451 \mathrm{~cm}^{-1}\right.$ in DL-serine [33]); $\omega \mathrm{CH}_{2}$ to four bands in the 1390 $1350 \mathrm{~cm}^{-1}$ region $\left(1375 / 1372 \mathrm{~cm}^{-1}\right.$ in DL-serine [33]); $\delta \mathrm{CH}$ to the band at $1339 \mathrm{~cm}^{-1}$ (with a shoulder at $1330 \mathrm{~cm}^{-1}$; in DL-serine: $1363 / 1355 \mathrm{~cm}^{-1}$ [33]); and $\gamma \mathrm{CH}$ to a set of bands in the $1315-1300 \mathrm{~cm}^{-1}\left(1321 / 1315 / 1303 \mathrm{~cm}^{-1}\right.$ in DL-serine [33]). It is worth noticing that the bands ascribed to the bending vibrations of both the $-\mathrm{CH}_{2}$ and $-\mathrm{CH}$ groups show a substantial dependence on temperature clearly indicating that these modes are considerably coupled with vibrations originating either in the $-\mathrm{NH}_{3}{ }^{+}$or $-\mathrm{OH}$ groups. In the Raman spectrum of Ser recorded at room temperature the bands associated with the $\delta \mathrm{CH}_{2}, \omega \mathrm{CH}_{2}, \delta \mathrm{CH}$ and $\gamma \mathrm{CH}$ modes are observed at 1461,1361 , 1345 and $1301 \mathrm{~cm}^{-1}$, respectively (Fig. 4).

\subsection{Region below $1275 \mathrm{~cm}^{-1}$ (Figs. 3 and 4)}

This spectral region is by far the most complex one in the spectra of the studied compounds. As it could be expected, the spectra of Ser90 and Ser70 are considerably more complex than that of Ser, because deuteration shifts several absorptions from the higher-frequency region to this lower-frequency region (e.g. for $\delta \mathrm{NH}, \gamma \mathrm{NH}$ and $\delta \mathrm{COH}$ modes). Furthermore, vibrational coupling is well known to be particularly important in the low frequency region of the spectra. This fact makes the assignment of bands to a single internal coordinate approximate, once usually several internal coordinates contribute significantly to the normal mode, even at the monomer level. In the following discussion, an approximate simplified description of the vibrations absorbing in this spectral range will be used, assuming in each case a dominant contribution. The main bands in the spectrum of Ser can, however be assigned relatively easily by comparison of the present data with those previously obtained for DL-serine crystal [33]. Then, the bands at 1090, $1022 / 1015,973,922,856,806,616,577$ and $531 \mathrm{~cm}^{-1}$ in the spectrum of L-serine correspond to those observed at 1096 , $1046 / 1034 / 1012,989 / 984,902,851,833 / 819,622,569 / 560$ and $539 / 514 / 512 \mathrm{~cm}^{-1}$ in the spectrum of DL-serine [33], and are assigned to the $\nu \mathrm{CO}, \mathrm{CH}_{2}, \nu \mathrm{CN}, \nu \mathrm{C}_{\alpha}-\mathrm{C}_{\beta}, \nu \mathrm{C}_{\alpha}-\mathrm{C}, \gamma \mathrm{COO}^{-}$, $\delta \mathrm{COO}^{-}, \omega \mathrm{COO}^{-}$and $\tau \mathrm{NH}_{3}{ }^{+}$modes, respectively. The patterns of variation of all these bands with change of temperature are consonant with the expectations, the bands due to $\nu \mathrm{CO}, \nu \mathrm{C}_{\alpha}-\mathrm{C}_{\beta}$ and $\nu C_{\alpha}-C$ being less sensitive to temperature (see Fig. 3), pointing to a more typical skeletal nature of these vibrations.

The assignment of the remaining bands in the spectrum of Ser is less obvious. The $\delta \mathrm{COH}$ vibration was assigned to the weak bands at 1224,1218 and $1209 \mathrm{~cm}^{-1}$, which show a pronounced temperature effect. It is worth mentioning that $\delta \mathrm{COH}$ appears at considerably lower wavenumbers in the vibrational spectra of L-serine when compared with DL-serine crystal, where it is observed at $1249 \mathrm{~cm}^{-1}$ [33]. This is in agreement with the much weaker $\mathrm{H}$-bond involving the $-\mathrm{CH}_{2} \mathrm{OH}$ side chain in L-serine crystal compared to that of DL-serine. Our assignment for this mode is also supported by the results previously obtained by Pawlukojć et al. [15], since no bands in the $1225-1200 \mathrm{~cm}^{-1}$ range were observed in the spectrum of L-serine- $\mathrm{D}_{4}$.

The rocking modes of the ammonium group $\left(\gamma \mathrm{NH}_{3}{ }^{+\prime}\right.$ and $\gamma \mathrm{NH}_{3}{ }^{+\prime \prime}$ ) were assigned to the bands at 1132 and $1126 \mathrm{~cm}^{-1}$, which decrease in relative intensity in the spectra of the deuterium-doped crystals. The band at $1132 \mathrm{~cm}^{-1}$ has a shoulder at higher-frequency ( $c a .1140 \mathrm{~cm}^{-1}$ ), which is here assigned to the $\mathrm{wCH}_{2}$ mode (Fig. 3). These three modes, i.e. $\gamma \mathrm{NH}_{3}{ }^{+\prime}, \gamma \mathrm{NH}_{3}{ }^{+\prime \prime}$ and twCH $\mathrm{H}_{2}$, are contributing to the band at $1137 \mathrm{~cm}^{-1}$ (with shoulder at $1143 \mathrm{~cm}^{-1}$ ) in the roomtemperature Raman spectrum of L-serine (see Fig. 4).

Finally, the $\tau \mathrm{OH}$ mode does also absorb in the spectral range above $400 \mathrm{~cm}^{-1}$ in infrared. Below $400 \mathrm{~cm}^{-1}$, the Raman spectrum of Ser shows four features, at 368, 303, 205 and $184 \mathrm{~cm}^{-1}$ (Fig. 4), which are assigned to the $\delta \mathrm{CCC}, \rho \mathrm{CCC}$, $\rho \mathrm{CCN}$ and $\rho \mathrm{COO}^{-}$modes, respectively, in agreement with the assignments previously proposed in Ref. [15] (see Table 1). As it could be anticipated, in L-serine crystal the $\tau \mathrm{OH}$ mode appears at a considerably lower-frequency than in DL-serine. In DL-serine, $\tau \mathrm{OH}$ appears at $744 \mathrm{~cm}^{-1}$ [33], a characteristic frequency for a $\tau \mathrm{OH}$ vibration of a hydroxyl group involved in a 
strong H-bond. In contrast, in the crystal of L-serine the hydroxyl group is practically "free" and $\tau \mathrm{OH}$ appears in the $500-420 \mathrm{~cm}^{-1}$ range $\left(438 \mathrm{~cm}^{-1}\right.$ in the room-temperature Raman spectrum of the single crystal). As expected, the bands ascribed to $\tau \mathrm{OH}$ show a pronounced temperature effect and decrease in relative intensity in the spectra of the deuteriumdoped crystals.

In the region below $1275 \mathrm{~cm}^{-1}$, the IR spectra of both Ser90 and Ser70 do also exhibit bands due to uncoupled deformational modes of the $-\mathrm{OD}$ and $-\mathrm{NDH}_{2}{ }^{+}$groups present in these crystals in minority amounts. In addition, some other vibrations originated in the minority deuterated zwitterions also contain significant contributions of the isotopically substituted groups, then giving rise to bands that appear slightly shifted relatively to the position for the same modes in the most abundant nondeuterated zwitterionic units.

The last group of additional bands present in Ser90 and Ser70 infrared spectra includes the satellite bands at 1202/1200/

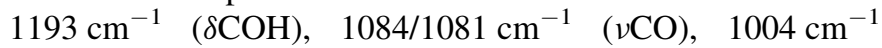
$\left(\gamma \mathrm{CH}_{2}\right), 958 \mathrm{~cm}^{-1}(\nu \mathrm{CN}), 945 / 935 \mathrm{~cm}^{-1}\left(\nu \mathrm{C}_{\alpha}-\mathrm{C}_{\beta}\right), 605 /$ $600 \mathrm{~cm}^{-1}\left(\delta \mathrm{COO}^{-}\right)$and $570 / 554 \mathrm{~cm}^{-1}\left(\omega \mathrm{COO}^{-}\right)$. In turn, the first group of bands includes: (i) the triplet of bands observed at 888,881 and $870 \mathrm{~cm}^{-1}$, which is due to the $\delta \mathrm{COD}$ mode of the minor deuterated molecules present in the crystals; (ii) the groups of bands observed at 1173/1170/1153, 1111/ 1098 and $1048 / 1038 \mathrm{~cm}^{-1}$, which correspond to the three uncoupled $\delta \mathrm{N}-\mathrm{D}$ vibrations of the $-\mathrm{NDH}_{2}{ }^{+}$deuterons involved in hydrogen-bonds of decreasing strength (i.e., bifurcated bond, bond 4 and bond 3 ); these bands appear at nearly the same frequencies as the equivalent vibrations in the deuterium-doped DL-serine crystal, where they were observed at 1144/1135, $1123 / 1115$ and $1079 \mathrm{~cm}^{-1}$, respectively [33] (note that this result stresses once again the conclusion that the $\mathrm{N}-\mathrm{H} \cdots \mathrm{O}$ intermolecular $\mathrm{H}$-bonds in L-serine and DL-serine crystals are quite similar, and that the different properties exhibited by the two crystals must be essentially a consequence of their different O-H. . O interactions); (iii) the bands at $844 \mathrm{~cm}^{-1}, 819 \mathrm{~cm}^{-1}$ (better seen in the $10 \mathrm{~K}$ spectrum of Ser90) and $780 \mathrm{~cm}^{-1}$, which are due to the uncoupled $\gamma \mathrm{N}-\mathrm{D}$ vibrations and whose specific assignment is discussed below; (iv) the band at $513 \mathrm{~cm}^{-1}$, which is tentatively assigned to the $\tau \mathrm{NDH}_{2}{ }^{+}$mode in the deuterated minority zwitterion units.

To assign the observed $\gamma \mathrm{N}-\mathrm{D}$ bands to individual bonds we made use of the general empirical correlation between the redshift of the uncoupled $\mathrm{N}-\mathrm{H}$ stretching bands in the crystal (relatively to the frequency of a similar mode in non-hydrogenbonded molecule) and the blue-shift in the band of the corresponding out-of-plane mode in the crystal (again relatively to the frequency of a similar mode in a nonhydrogen-bonded molecule) [44]. Following conventional Herzberg's notation, the stretching modes will be here designated as $v_{1}$, while the out-of-plane rocking modes as $v_{4}$. The red-shift of $v_{1}$ and the blue-shift of $v_{4}$ bands associated with a given $\mathrm{H}$-bond proton correlate to each other as $\Delta v_{4}^{2}=2.5\left(\Delta v_{1}\right)^{1 / 2}-18$, where $\Delta v_{4}^{2} \equiv 10^{-4}\left[\left(v_{4}\right)^{2}-\left(v_{4}^{0}\right)^{2}\right]$ and $\Delta v_{1}=v_{1}^{0}-v_{1}$ (both $v_{1}$ and $v_{4}$ are expressed in $\mathrm{cm}^{-1}$ ) [44]. Taken the $\nu_{1}^{0}$ and $\nu_{4}^{0}$ reference values, respectively, equal to
3450 and $1000 \mathrm{~cm}^{-1}$, which correspond to rounded average values for free $\mathrm{N}-\mathrm{H}$ amine stretching and rocking vibrations in amines, amino acids and other compounds bearing amino or protonated amino groups [16,33,34,42,45-47], the three out-ofplane uncoupled vibrations originating from individual $\mathrm{NH}$ groups are predicted to occur at 1158,1145 and $1132 \mathrm{~cm}^{-1}$. These frequencies can be associated with the three progressively weaker $\mathrm{N}-\mathrm{H} \cdots \mathrm{O}_{\text {Carboxyl }}$ bonds observed in the crystal of $\mathrm{L}$-serine. If we take into account the frequency isotopic ratio $(\gamma \mathrm{N}-\mathrm{H} / \gamma \mathrm{N}-\mathrm{D})$ of 1.41 observed for these modes in DL-serine crystal [33], the counterparts of these bands in the spectrum of deuterium-doped L-serine crystals, i.e. the bands due to the three out-of-plane uncoupled vibrations originated in individual N-D bonds, are expected to occur at 821, 812 and $803 \mathrm{~cm}^{-1}$. These predicted frequencies closely match the positions of bands observed at 844,819 and $780 \mathrm{~cm}^{-1}$, which can then be ascribed to the uncoupled $\gamma \mathrm{N}-\mathrm{D}$ modes of the groups involved in the bifurcated hydrogen-bond, bond 4 and bond 3 , respectively.

Use of the empirical correlation between $v_{1}$ and $v_{4}$ to estimate the frequency of the $\tau$ OD mode (with $v_{1}^{0}$ and $v_{4}^{0}$ reference values of 3640 and $300 \mathrm{~cm}^{-1}$ [33]), yields the value $306 \mathrm{~cm}^{-1}$, which is below the accessible spectral region of our infrared instrument.

A final note should also be made regarding the observed shift of the band observed at $476 \mathrm{~cm}^{-1}$ in the low-temperature infrared spectrum of Ser, to $462 \mathrm{~cm}^{-1}$, in the spectra of the deuterium-doped crystals. As mentioned above, this band is the lowest-intensity component of the group of bands ascribed to $\tau \mathrm{OH}$ (see Fig. 3 and Table 1). Though the following explanation for the observed shift must be considered only as tentative, it is possible that it results from a reduction in the degree of an anharmonic interaction (e.g., Fermi resonance) of $\tau \mathrm{OH}$ with an overtone of a lower-frequency mode due to deuteration. Indeed, deuteration could lead to a frequency shift in the interacting low frequency mode reducing the frequency matching between its overtone and the $\tau \mathrm{OH}$ fundamental and, consequently, the anharmonic coupling, thus changing the relative positions of the bands resulting from this interaction; the lowest-intensity band could then be expected to exhibit the largest-frequency shift, consonant with the observations.

\subsection{Spectra/H-bond distances and spectra/H-bond energies correlations}

The observed frequency red-shifts of the $v_{1}$ stretching modes upon $\mathrm{H}$-bond formation and the corresponding $\mathrm{H}$-bond lengths $\left(r_{\mathrm{H} \cdots \mathrm{B}}\right)$ were shown to obey the empirical correlation expressed as $\Delta v_{1} / \mathrm{cm}^{-1}=0.011\left(r_{\mathrm{H} \cdots \mathrm{B}} / \mathrm{nm}\right)^{-6.1}[35,48]$. This expression was shown to describe successfully the experimental data collected for a considerable number of H-bonded systems, including crystalline carbohydrates [36,49], nucleobases (cytosine [50], uracil and thymine [51]), nucleosides (cytidine [52], adenosine and uridine [53]) and several amino acids (glycine, alanine, glutamine, histidine, tyrosine and threonine $[34,46])$. This empirical correlation was also successfully applied to crystalline DL-serine [33]. 
The H-bond distances estimated from the IR spectra using the empirical correlation for the three non-equivalent single $\mathrm{H}$-bonds in crystalline L-serine experimentally found by diffraction methods are $2.15 \AA$ (bond 5; O-H - . O), $1.86 \AA$ (bond 3) and $1.81 \AA$ (bond 4), fairly reproducing the experimental values $[4,6,7]$. Indeed, in the case of the $\mathrm{O}-\mathrm{H}$. . O H-bond distance (bond 5) the estimated value agrees very well with the average experimental value (2.111 $)$ ), whereas the estimated values for the $\mathrm{N}-\mathrm{H} \cdots \mathrm{O}$ bonds are slightly underestimated (by $c a$. $0.1 \AA$, relative error within $c a$. $5 \%$ ). Strictly, the correlation cannot be applied to a bifurcated bond, since the frequency shift results from the added effect of the two individual hydrogen-bonds. However, since as revealed by the structural methods [4,6,7] for L-serine one of the branches of the bifurcated hydrogen-bond is considerably shorter than the other, we also tried to use the empirical relationship above as a way to estimate the length of the shorter branch of the bifurcated hydrogen-bond. Though being within a $10 \%$ relative error when compared to the average experimental value $(1.934 \AA[4,6,7])$, the resulting value, $1.77 \AA$, is much worse when compared with the estimations for the remaining H-bond distances. This clearly reveals the structural significance of the second 'component' of the bifurcated bond.

It is also possible to estimate thermodynamic properties related with $\mathrm{H}$-bonds from the spectroscopic data using the empirical correlations between the H-bond energy and (i) the blue-shift of the $v_{4}$ mode bands $\left\{-\Delta H=0.67 \Delta v_{4}^{2}\right.$, where $\Delta v_{4}^{2} \equiv$ $10^{-4}\left[\left(v_{4}\right)^{2}-\left(v_{4}^{0}\right)^{2}\right] ; v_{4}$ is expressed in $\mathrm{cm}^{-1}$ and $\Delta H$ in $\left.\mathrm{kJ} \mathrm{mol}^{-1}\right\}$ $[36,38]$ or (ii) the red-shift of the stretching vibration of the H-bond donor group $\left\{\left(\Delta H / \mathrm{kJ} \mathrm{mol}^{-1}\right)^{2}=1.92\left(\Delta v_{1} / \mathrm{cm}^{-1}-40\right)\right\}$ [37]. In the case of the L-serine crystal, the average H-bond energies resulting from the two empirical correlations above presented are $10,20,23$ and $25 \mathrm{~kJ} \mathrm{~mol}^{-1}$, respectively, for the $\mathrm{O}-\mathrm{H} \cdots \mathrm{O}$ and the three $\mathrm{N}-\mathrm{H} \cdots \mathrm{O}$ H-bonds (bond 3, bond 4 and bifurcated bond, respectively), which correspond to a total enthalpy of $79 \mathrm{~kJ} \mathrm{~mol}^{-1}$. This value is smaller than that previously estimated for DL-serine $\left(101 \mathrm{~kJ} \mathrm{~mol}^{-1}\right.$ [33]), as expected taking into consideration the different properties exhibited by the crystals of L-serine and DL-serine, in particular the greater structural stability of the latter crystal upon the increase of external pressure [7,8] and melting points (222 and $240{ }^{\circ} \mathrm{C}$, for L- and DL-serine crystals, respectively [54]).

\section{Conclusion}

In this study, the IR spectra of polycrystalline samples of L-serine with naturally occurring isotopic contents and doped with deuterium ( $\leq 10$ and $\cong 30 \%$ deuterium contents) were investigated in the range $4000-400 \mathrm{~cm}^{-1}$, at temperatures varying from 300 to $10 \mathrm{~K}$. The Raman spectrum of single crystal sample of L-serine with naturally occurring isotopic contents was also investigated in the range $4000-150 \mathrm{~cm}^{-1}$, at room temperature. The full assignment of the spectra is presented. The isotopic-doping/low-temperature methodology, allowed the identification in the spectrum of the deuteriumdoped crystals of bands associated with individual (uncoupled) deuterium vibrational modes. From these data, estimations of the energies of the different H-bonds present in L-serine crystal, as well as H-bond lengths, were made using well-known empirical correlations [34-38]. A systematic comparison between the presently obtained results on L-serine with the data previously obtained for DL-serine revealed that the vibrational spectra of the two crystals reflect well the different characteristics of their $\mathrm{H}$-bond networks and do also correlate well with the different susceptibility of the two crystals to pressure-induced strain.

\section{Acknowledgments}

This work was financially supported by "Fundação para a Ciência e a Tecnologia" (FCT_Projects POCTI/QUI/59019/ 2004 and POCTI/QUI/58937/2004) and GRICES/SECyT (Project 000813//PO-PA04-EVI/001). SJ and IR also acknowledge FCT for the Grants SFRH/BD/6696/2001 and SFRH/ BPD/1661/2000.

\section{References}

[1] S. Jarmelo, L. Lapinski, M. Nowak, P.R. Carey, R. Fausto, J. Phys. Chem. A 109 (2005) 5689.

[2] S. Jarmelo, R. Fausto, J. Mol. Struct. 786 (2006) 175-181.

[3] G. Albrecht, G.W. Schnakenberg, M.S. Dunn, J.D. McCullough, J. Phys. Chem. 47 (1943) 24.

[4] E. Benedetti, C. Pedone, A. Sirigu, Cryst. Struct. Commun. 1 (1972) 35.

[5] S. Ramakumar, K. Venkatesan, N. Shamala, Indian J. Pure Appl. Phys. 11 (1973) 461.

[6] T.J. Kistenmacher, G.A. Rand, R.E. Marsh, Acta Crystallogr. B 30 (1974) 2573.

[7] E.V. Boldyreva, E.N. Kolesnik, T.N. Drebushchak, H. Ahsbahs, J. Ares Beukes, H.-P. Weber, Z. Kristallogr. 220 (2005) 58.

[8] E.V. Boldyreva, E.N. Kolesnik, T.N. Drebushchak, H. Sowa, H. Ahsbahs, Y.V. Seryotkin, Z. Kristallogr. 221 (2006) 150.

[9] E.N. Kolesnik, S.V. Goryainov, E.V. Boldyreva, Doklady Phys. Chem. 404 (2005) 169.

[10] S.A. Moggach, D.R. Allan, C.A. Morrison, S. Parsons, L. Sawyer, Acta Crystallogr. B 61 (2005) 58.

[11] R.S. Krishnan, V.N. Sankaranarayanan, K. Krishnan, J. Indian Inst. Sci. 55 (1973) 66.

[12] C. Madec, J. Lauransan, C. Garrigou-Lagrange, Compt. Rend. Hebd. Sea. Acad. Sci. B 288 (1979) 69.

[13] S.K. Husain, J.B. Hasted, D. Rosen, E. Nicol, J.R. Birch, Infrared Phys. 24 (1984) 201.

[14] T.M. Korter, R. Balu, M.B. Campbell, M.C. Beard, S.K. Gregurick, E.J. Heilweil, Chem. Phys. Lett. 418 (2006) 65.

[15] A. Pawlukojć, J. Leciejewicz, J. Tomkinson, S.F. Parker, Spectrochim. Acta A 58 (2002) 2897.

[16] S.G. Stepanian, I.D. Reva, E.D. Radchenko, M.T.S. Rosado, M.L.T.S. Duarte, R. Fausto, L. Adamowicz, J. Phys. Chem. A 102 (1998) 1041.

[17] Y. Ding, K. Krogh-Jespersen, Chem. Phys. Lett. 199 (1992) 261.

[18] M.T.S. Rosado, M.L.R.S. Duarte, R. Fausto, J. Mol. Struct. 410 (1997) 343.

[19] J. Parra-Mouchet, W.H. Fink, C.P. Nash, J. Phys. Chem. 89 (1985) 524.

[20] M.A. Peterson, H. Hope, C.P. Nash, J. Am. Chem. Soc. 101 (1979) 946.

[21] I.-S. Jeon, D.-S. Ahn, S.-W. Park, S. Lee, S. Kyu Kim, Chem. Phys. Lett. 403 (2005) 72.

[22] F.J. Ramírez, I. Tuñón, E. Silla, Chem. Phys. 303 (2004) 85.

[23] F.R. Tortonda, E. Silla, I. Tunón, D. Rinaldi, M.F. Ruiz-López, Theor. Chem. Acc. 104 (2000) 89.

[24] D. Chakraborty, S. Manogaran, J. Mol. Struct. (THEOCHEM) 429 (1998) 31. 
[25] O. Kikuchi, T. Matsuoka, H. Sawahata, O. Takahashi, J. Mol. Struct. (THEOCHEM) 305 (1994) 79.

[26] O. Kikuchi, T. Matsuoka, T. Kozaki, J. Mol. Struct. (THEOCHEM) 207 (1990) 103.

[27] M. Pecul, Chem. Phys. Lett. 418 (2006) 1.

[28] L. Carozzo, G. Corongiu, C. Petrongolo, E. Clementi, J. Chem. Phys. 68 (1978) 787.

[29] E. Clementi, F. Cavallone, R. Scordamaglia, J. Am. Chem. Soc. 99 (1977) 5531.

[30] A.V. Iogansen, Izvestiya Akademii Nauk SSSR Seriya Fizicheskaya (Engl. Transl. 1989 by Allerton Press, Inc.) 53 (1989) 1741.

[31] A.V. Iogansen, M. Rozenberg, J. Struct. Chem. (USSR) 30 (1989) 76.

[32] M. Rozenberg, A.V. Iogansen, Opt. Spectrosc. (USSR) 64 (1988) 693.

[33] S. Jarmelo, I. Reva, M. Rozenberg, P.R. Carey, R. Fausto, Vibrat. Spectrosc. 41 (2006) 73.

[34] M. Rozenberg, G. Shoham, I. Reva, R. Fausto, Phys. Chem. Chem. Phys. 7 (2005) 2376.

[35] M. Rozenberg, A. Loewenschuss, Y. Marcus, Phys. Chem. Chem. Phys. 2 (2000) 2699.

[36] M. Rozenberg, A. Loewenschuss, H.-D. Lutz, Y. Marcus, Carbohydr. Res. 315 (1999) 89.

[37] A.V. Iogansen, Spectrochim. Acta A 55 (1999) 1585.

[38] M. Rozenberg, A.V. Iogansen, A.A. Mashkovsky, S.E. Odinokov, Spectrosc. Lett. 5 (1972) 75.

[39] J. Dong, D. Dinankarpandian, P.R. Carey, Appl. Spectrosc. 52 (1998) 1117.
[40] P.R. Carey, J. Dong, Biochemistry 43 (2004) 8885.

[41] M.N. Frey, M.S. Lehmann, T.F. Koetzle, W.C. Hamilton, Acta Crystallogr. B 29 (1973) 876.

[42] M.T.S. Rosado, Estrutura Molecular e Espectros Vibracionais de $n$ - e $\alpha$ Aminoácidos Simples, Ph.D. Thesis, University of Lisbon, Portugal, 2004.

[43] K. Machida, M. Izumi, A. Kagayama, Spectrochim. Acta A 35 (1979) 1333.

[44] M.S. Rozenberg, Spectrochim. Acta A 52 (1996) 1559.

[45] G. Fischer, X.L. Cao, N. Cox, M. Francis, Chem. Phys. 313 (2005) 39.

[46] M. Rozenberg, G. Shoham, I. Reva, R. Fausto, Spectrochim. Acta A 59 (2003) 3253.

[47] S.G. Stepanian, I.D. Reva, E.D. Radchenko, L. Adamowicz, J. Phys. Chem. A 103 (1999) 4404.

[48] M. Rozenberg, C. Jung, G. Shoham, Phys. Chem. Chem. Phys. 5 (2003) 1533.

[49] M. Rozenberg, A. Loewenschuss, Y. Marcus, Carbohydr. Res. 328 (2000) 307.

[50] M. Rozenberg, G. Shoham, I. Reva, R. Fausto, Spectrochim. Acta A 60 (2004) 463.

[51] M. Rozenberg, G. Shoham, I. Reva, R. Fausto, Spectrochim. Acta A 60 (2004) 2319.

[52] M. Rozenberg, C. Jung, G. Shoham, Spectrochim. Acta A 60 (2004) 2369.

[53] M. Rozenberg, C. Jung, G. Shoham, Spectrochim. Acta A 61 (2005) 733.

[54] Sigma-Aldrich Catalogue of Chemicals, 2006-2007, http://www. sigmaaldrich.com. 